\title{
Effect of Curriculum Planning for Physical Education in Colleges on Innovation Ability
}

\author{
https://doi.org/10.3991/ijet.v15i12.14527 \\ Huiqiu Guo \\ Sports Department of Northeast Agricultural University, Harbin, China \\ huiqiuguo@163.com
}

\begin{abstract}
With poor integrity and unclear goals, the curriculum planning for physical education (PE) in colleges cannot effectively promote the innovation ability of students. To solve the problem, this paper attempts to clearly evaluate the effect of curriculum planning for college PE on the innovation ability of PE majors. Based on the defects of the current curriculum planning, the authors put forward several strategies and suggestions to enhance the promoting effect of college PE curriculum planning on innovation ability. Following the fuzzy theory, an index system and a fuzzy evaluation model were put forward to quantify the effect of college PE curriculum planning on innovation ability. The research results have great theoretical and practical significance.
\end{abstract}

Keywords—Physical education (PE), curriculum planning, innovation ability, colleges, effect analysis

\section{$1 \quad$ Introduction}

$\mathrm{PE}$ is an important part of higher education. It plays a very important role in enhancing the physical quality of college students and improving their comprehensive ability. With the implementation of quality education in modern society, more and more colleges have begun to focus on cultivating college students' sports quality [13]. As the main component of the comprehensive ability for contemporary college students, innovation ability plays an indispensable role in improving their comprehensive quality. It is not only the main promoter of deepening the knowledge system of college students, but also an important catalyst to improve their ability in other aspects [4-6]. And the curriculum planning has a direct effect on training college students' innovation ability. Its appropriateness determines the training quality of college students' innovation ability. Especially the current society's urgent demands for senior PE professionals cause more and more researchers to carry out multi-perspective research and analysis on this. Forey and Cheung, [7] discussed the advantages of explicit language teaching in PE classrooms to PE learning. Egan et al. [8] analyzed the problem of setting up comprehensive sports activities in schools based on healthoptimized sports. Zeng and $\mathrm{Li}$, [9] took a university as an example and analyzed the innovation and practice of its PE curriculum construction with science and technology 
characteristics. Zhang [10] explored the college PE curriculum reform from the perspective of competency-based education. Cong and Wang [11] analyzed how to reform the PE curriculum under the talent training system of applied universities. Wang and Zhu, [12] studied the basketball teaching model under the new sports curriculum reform in colleges by using a college as an application case. Parson et al. [13] analyzed the way of using competency-based curriculum design and then established a health professional education certificate program to meet the needs of faculty and managers etc.

However, due to different research perspectives, researchers' analysis for the college PE curriculum planning oriented to innovative ability is often not systematic and complete. There are also some limitations in its implementation. Based on the results of the previous research, this paper further analyzes the key content of the college PE curriculum planning for the cultivation of innovation ability, and then constructs a corresponding fuzzy quantitative analysis model based on the fuzzy theory [14-15]. This consists of five parts. The first part gives an overview and analysis of current issues about college PE curriculum planning; the second part analyzes the promotion effect of college PE curriculum planning on the cultivation of innovation ability; the third part proposes some strategies and suggestions for college PE curriculum planning with the goal of cultivating innovative ability; the fourth part quantitatively analyzes the training effect of the PE major students' innovation ability in colleges based on professional curriculum planning, and establishes an index system and a fuzzy evaluation model; the fifth part draws the conclusion.

\section{Analysis for the Promotion Effect of College PE Curriculum Planning on the Cultivation of Innovation Ability}

\subsection{Performance of PE major students' innovation ability in colleges}

Innovation ability plays a very important role in cultivating the comprehensive ability of senior PE professionals in colleges. The author believes that the innovation ability of PE major students in colleges is not only a direct manifestation of innovative consciousness, but also a structure system of comprehensive ability, which has a direct or indirect relationship with the cultivation of their other abilities. Aimed at cultivating the comprehensive quality of PE major students, their innovation ability should be reflected in the following aspects: (1) Sports innovation consciousness; innovation consciousness is the source of motivation for innovation results; college PE majors without innovation consciousness will not be able to effectively capture the soul of sports professional innovation, nor can they conduct in-depth professional development. (2) Absorptive capacity of sports professional knowledge; the prerequisite for innovation of PE major students is certain professional knowledge reserve, and the absorptive capacity of professional knowledge is positively correlated with the knowledge reserve. (3) Transformation ability of sports professional knowledge; only through effective transformation and expansion of sports professional knowledge can innovative value be generated. (4) Good athletic ability and physical function, 
focus must be placed on cultivating the basic elements of sports performance, the essentials of movement, the coordination of movements, the flexibility of movements, the rhythm sensation of movements, the spaciousness of movements, and so on, providing physical guarantee for development and training of PE innovation ability in colleges. (5) The training of sports professional skills, that is, attention must be paid to the continuity, systematicness, sensitivity, comprehension, operability, and changeability of professional skills, which is the lubricant for PE major innovation. The PE major innovation is not an individual activity, but a group cooperation project. Therefore, the professional innovation ability of college PE major students should be cultivated to ensure that each team member has good teamwork and communication skills, self-awareness and adaptability. In addition, the PE in colleges is developed to cultivate useful senior PE professionals for the society, which can meet the development needs of the society, and have certain benefits or contribute to improving the comprehensive sports quality of social groups. For this, the innovation ability of PE students in colleges also reflects their employment competitiveness and social service ability.

\subsection{Promoting effect of PE curriculum on the cultivation of innovation ability}

PE curriculum in colleges generally includes professional knowledge in different learning levels and directions. They are often a high concentration and extraction of sports professional knowledge, providing a wealth of professional knowledge reserves and quality development for senior PE professionals. Therefore, from this perspective, the curriculum planning of PE major is the development outline for training PE professionals in colleges. It is the key link for cultivating PE professional talents and also the essence of their innovation ability. Through inductive analysis, the author believes that the promotion effect of the PE curriculum on innovation ability of the PE major students is reflected in the following aspects: First, promote innovative consciousness and cultivate scientific attitude; the senior PE professionals trained in colleges must have a correct scientific attitude and a keen sense of innovation, which is a necessary condition for the sustainable development of senior PE professionals. Therefore, the planning of PE curriculum in colleges must also be carried out. (2) Improve physical fitness, which is the most basic purpose of developing PE curriculum in colleges; the PE curriculum planning in colleges must also take physical training and enhancement of college students as the basic starting point. (3) Enhance professional knowledge and professional skills; in addition to improving the physical fitness of college student groups, another focus of the PE curriculum planning in colleges is on cultivating PE professional and fostering a comprehensive business for society. In the training process of senior PE professionals, it's important to improve the professional knowledge and professional skills of college PE major students. (4) Improve employment competitiveness; there are often some sports competitions or scientific practice activities in the course setting or planning of PE majors, which can improve their professional and technical capabilities. This shall provide great help in the subsequent employment or entrepreneurship process. (4) Promote social adaptability; the PE curriculum setting or planning generally includes two parts, namely the theoretical curriculum and the practical curriculum; the former focuses on the transfer of theoretical knowledge 
for the PE major, while the latter needs to be integrated with the theoretical knowledge, and consolidate, deepen and expand professional knowledge in practical courses; the practical curriculum emphasizes on the teaching of sports action and sports skills operation in different situations or environments, which is more conducive to cultivating the adaptability of PE students in these training environments or conditions. (5) Improve team collaboration ability; PE professional skills and movements cannot be completed by one single student, but often require good communication and collaboration between team members. In this process, it will be very beneficial to the cultivation of team collaboration ability for college PE majors.

\subsection{Current defects and problems}

Base on survey research on the current status of the PE teaching and scientific research in colleges, and also the statistical and inductive analysis of relevant survey information and research results, it's found that there are still many problems and defects in the development and implementation of PE curriculum in college. They are mainly reflected in the following aspects:

The basic teaching conditions of PE curriculums are weak: The human, material and financial resources of colleges are often weak in the construction of PE major. Not only can they be able to form a team of PE faculty with a high degree of professional literacy and strong business abilities, but also the software and hardware facilities in terms of basic physical education and scientific research are often not complete enough, which has greatly affected the development of the teaching and scientific research for PE major in colleges.

The training objectives of the PE curriculum are not clear, and the management doesn't pay enough attention: Unlike science and engineering majors, the PE major cannot bring about considerable scientific research funds or social benefits to the colleges. This has led to the insufficient attention of the college management to the PE teaching and scientific research. Thus, a relatively complete and standardized system cannot be formed, failing to provide a strong policy guarantee for the teaching and scientific research of PE major. Also, the training goal is often not clear. It is unclear to implement exam-oriented education or quality education, and to train professionals or generalists.

PE curriculums cannot arouse the learning interest of PE major students in colleges: There are multiple reasons for the low learning interest of PE major students, but the main reasons can be summarized: One is that the teaching of PE curriculum or professional knowledge cannot resonate with the students, and the teaching effect and teaching atmosphere are poor; the second is that in the learning process, the PE major students are not sufficiently motivated to learning, and have no clear prospect for the subsequent development and application of the professional courses or professional knowledge learned, lacking the necessary understanding of the social needs for the PE development. The above two reasons are generally reflected in the following aspects: First, the teaching content of PE major is disjointed from the needs of students, and the setting or planning of PE curriculum cannot fully consider the interests of PE major students, as well as the physical fitness needs, academic needs, 
and employment needs. Second, the teaching methods of PE curriculum are outdated and cannot keep up with the development of the times. There is still a large shortage of modern technology in usage and integration with the PE teaching. Third, there is a disconnection between the theoretical teaching and practical teaching of the PE curriculum. Although the theoretical curriculum and the practical curriculum are divided in the PE curriculum, they are often independent in the specific teaching process, and the content is not well connected and integrated.

The PE curriculum is not systematic: The current PE curriculum setting in colleges often only focuses on the development of local curriculum content or teaching links, and cannot form a scientific PE curriculum system from an overall perspective. The professional knowledge is not systematic and complete.

\section{Strategies and Suggestions for the College PE Curriculum Planning to Cultivate the Innovation Ability}

\subsection{PE curriculum planning must be targeted}

To ensure a good training effect of innovation ability for PE talents, the primary factor of curriculum planning is to have a specific target. For this, it's necessary to grasp the four orientations in the planning process, that is, the orientations of talents, curriculum, management and teaching philosophy.

The curriculum orientation is to require clarifying the professional level and logic of the PE curriculum, and to make sure which courses focus on the transfer of sports theoretical knowledge, which courses are oriented to the transfer of sports practice knowledge, which courses need good professional knowledge reserve, which courses need to have good professional skills and operation ability, which courses need to have good cohesion and integration, which courses emphasize on the cultivation of sports technical movements and level of training, and which courses focus on the training of sports professional skills and training level.

The talent orientation is to require clarifying the type of PE talents in the PE curriculum planning, i.e., the applied talents or academic talents, technical talents or general talents; examination-oriented education or quality-oriented education, or a combination of examination-oriented education and quality-oriented education for physical education majors.

The teaching concept orientation in the PE curriculum planning is to require clarifying the basic characteristics and laws of the PE teaching and scientific research activities, and having a deeper scientific understanding and objective cognition of the PE curriculum implementation process. On this basis, it can form or acquire the scientific, reasonable, and objective teaching objectives, teaching content, teaching mode, and teaching methods, etc. as the key content or links.

Management orientation is to require clarifying relevant rules and regulations in the implementation of PE curriculum, such as the rights, responsibilities and obligations of leaders in the PE curriculum planning process, the work content, work scope, work mechanism, and work attitude of service personnel, and the responsibilities, 
obligations, and performance in management, professional teaching, scientific research, and other aspects of management and faculty during the PE curriculum teaching.

\subsection{PE curriculum planning must be effective}

Due to the rapid development of modern society, especially the continuous progress of science and technology, many emerging intelligent technologies has emerged, which not only changes the way of life and work of social groups, but also has a great impact on the exercise mode of social groups. The group's perception of sports is not only the physical fitness, but also more emphasis on the sports professional skills or sports professional technical movements. This understanding also continuously deepens with the dynamic nature of social development. Thus, colleges must take into account the needs of social development for PE professionals in the PE curriculum setting or planning, and well perform implementation plan of PE curriculum based on the characteristics of the times, so that the development of PE major is in line with the mainstream of social development.

\subsection{PE curriculum planning must be professionally oriented}

Quality-oriented education is the mainstream form of modern higher education. At present, the setting of PE curriculum in colleges is also mainly quality-oriented education for PE major students. This requires that the PE curriculum planning for PE talents must have a strong professional orientation and be based on a quality education model no matter whether it is oriented to the cultivation of professional technical personnel or general talent training, applied sports professionals or academic professionals. The authors believe that the professional orientation in PE curriculum planning needs to be ensured in the following aspects. First of all, clarifying the professional orientation of PE curriculum planning is conducive to the cultivation of the PE major students' professional ability, especially the innovation ability. Secondly, the professional orientation of the PE curriculum planning needs to fit curriculum forms. There are many forms of PE curriculums, including theory courses, practical courses, curriculum design, internships of graduation projects, and physical education academic activities, and each form of PE activities should have a corresponding professional orientation. Furthermore, it should reflect the richness and epochal nature of related teaching content, the advancement of teaching methods, and diversity and intelligence of teaching methods in the implementation process of PE-related majors.

\subsection{PE curriculum planning must be integrative}

PE curriculum planning in colleges is systematic, so it is necessary to integrate different types, levels and forms of PE curriculum into an organic whole from a holistic perspective, that is, PE curriculum planning must be integrative. In this study, the integration of PE curriculum planning is mainly reflected in the following aspects: first, integrate the elective and compulsory courses; the compulsory courses of the PE 
major focus on the transfer of the necessary knowledge, which is the basic knowledge that all students must master, and the elective courses allow the students with more ability to further absorb the PE professional knowledge; the integration of the two is conducive to broadening the perspective of PE major students. Second, integrate the theoretical and practical courses; the theoretical courses emphasize on the transfer of theoretical knowledge, while the practical courses on the transfer of practical knowledge. It's well known that theoretical knowledge is the extraction and improvement of practical knowledge, and practice knowledge is the verification and deepening of theoretical knowledge, which are complementary. Third, integrate the issue courses and basic courses; the former focuses on the deep excavation of sports professional knowledge, and the latter on their breadth excavation. The integration of the two is conducive to improving the knowledge reserve capacity of sports talents, which can greatly promote the training of the PE talents' innovation ability. Fourth, integrate the PE teaching and scientific research; in higher education, teaching and scientific research are the two most important parts, which two have a very close relationship. PE teaching provides a channel for knowledge transmission in the training of PE professionals, and activities and projects provide a way of results transformation for the training of PE professionals. Both are indispensable means to effectively enhance the innovation ability of contemporary sports professionals. Especially with the emergence of many intelligent technologies, it also provides a good platform for the integration of the both.

\subsection{The PE curriculum planning must be logical}

The PE curriculum planning must take into account the actual conditions such as PE teachers' level and students' learning abilities, as well as various factors, including the specific teaching environment, teaching conditions, learning environment, and learning atmosphere. It can be analyzed from two perspectives. First, from the perspective of teacher teaching, it is necessary to form a PE curriculum teaching system consisting of a syllabus, a teaching plan, a teaching log, a teaching report, a teaching summary, and a teaching assessment, and focus on the construction of high-quality courses; also, the PE faculty should be enhanced in different aspects, especially the construction of teacher team talents and professional training of teachers, so as to better promote the transfer of sports professional knowledge. Second, from the perspective of PE college students, it is necessary to classify their professional knowledge into different levels according to the personal interests of PE college students, and form a learning system for undergraduates and graduate students of different grades; then, according to the difficulty degree of PE professional knowledge teaching, we should do well in the cohesion of sports professional knowledge, and follow a gradual learning model in the training of professional technical movements and professional skills. 


\section{Effect Analysis for the Innovation Ability Training of PE Major Students Based on PE Curriculum Planning}

\subsection{Determination of evaluation index set}

Based on the above, the effects of PE curriculum planning on the cultivation of innovative ability are reflected in many aspects. These can be selected as corresponding evaluation indicators, that is, the sports innovation awareness $\mathrm{C} 1$, absorptive capacity of sports professional knowledge $\mathrm{C} 2$, ability to transform sports professional knowledge $\mathrm{C} 3$, physical function $\mathrm{C} 4$, athletic ability $\mathrm{C}$, sports professional skills $\mathrm{C} 6$, teamwork and communication ability $\mathrm{C} 7$, self-awareness and adaptability $\mathrm{C} 8$, employment competitiveness $\mathrm{C} 9$ and social service ability $\mathrm{C} 10$. Then, the evaluation index set $\mathrm{C}$ can be expressed as:

$$
\mathbf{C}=\left\{C_{1}, C_{2}, C_{3}, C_{4}, C_{5}, C_{6}, C_{7}, C_{8}, C_{9}, C_{10}\right\}
$$

In this evaluation index set, different evaluation indexes may have different importance. Using weight acquisition methods such as AHP method [16-18], entropy weight method [19-21], etc., the corresponding index weight set can be obtained. This shall provide supports for the subsequent analysis of the training effect of the PE majors' innovation ability based on professional curriculum planning.

\subsection{Normalization of evaluation index}

Considering the uncertainty of the evaluation index value, this paper analyzes the normalized index with interval value, that is, the evaluation object P's measurement value for the evaluation index $\mathrm{i}$ is $V_{P}\left(C_{i}\right)=\left[v_{P}^{a}\left(C_{i}\right), v_{P}^{b}\left(C_{i}\right)\right]$. If this index is a benefit-based index, its normalized value $\overline{\bar{V}}_{P}\left(C_{i}\right)$ is shown as:

$$
\begin{aligned}
& \overline{\bar{V}}_{P}\left(C_{i}\right)=\left[\begin{array}{l}
=a \\
v_{P}
\end{array}\left(C_{i}\right), v_{P}\left(C_{i}\right)\right]= \\
& \left(\frac{v_{P}^{a}\left(C_{i}\right)-V_{P}^{\nabla}\left(C_{i}\right)}{V_{P}^{\Delta}\left(C_{i}\right)-V_{P}^{\nabla}\left(C_{i}\right)}, \frac{v_{P}^{b}\left(C_{i}\right)-V_{P}^{\nabla}\left(C_{i}\right)}{V_{P}^{\Delta}\left(C_{i}\right)-V_{P}^{\nabla}\left(C_{i}\right)}\right)
\end{aligned}
$$

where, $V_{P}^{\Delta}\left(C_{i}\right)$ is the maximum value of the evaluation index i, and $V_{P}^{\nabla}\left(C_{i}\right)$ is its minimum value.

If it's a cost-based index, its normalized value $\overline{\bar{V}}_{P}\left(C_{i}\right)$ is: 


$$
\begin{aligned}
& \overline{\bar{V}}_{P}\left(C_{i}\right)=\left[\begin{array}{l}
=a \\
v_{P}
\end{array}\left(C_{i}\right), v_{P}\left(C_{i}\right)\right]= \\
& \left(\frac{V_{P}^{\Delta}\left(C_{i}\right)-v_{P}^{b}\left(C_{i}\right)}{V_{P}^{\Delta}\left(C_{i}\right)-V_{P}^{\nabla}\left(C_{i}\right)}, \frac{V_{P}^{\Delta}\left(C_{i}\right)-v_{P}^{a}\left(C_{i}\right)}{V_{P}^{\Delta}\left(C_{i}\right)-V_{P}^{\nabla}\left(C_{i}\right)}\right)
\end{aligned}
$$

It can be seen that the normalized evaluation index values all meet $[0,1]$, and have unified measurement standards, which eliminates the differences between the evaluation indexes, and is more conducive to improving the accuracy of evaluation results.

\subsection{Classification of evaluation levels}

To ensure a better analysis for the effect of PE curriculum planning on PE major students' innovation ability, the authors analyzed the evaluation level accordingly. Generally, too large or too small the granularity of evaluation levels is not conducive to the improvement of evaluation resolution, and affects the reliability of evaluation results. To this end, this study classified it into five levels: excellent G1, good G2, medium G3, average G4, and poor G5. The set of evaluation levels G is expressed as:

$$
\mathbf{G}=\left\{G_{1}, G_{2}, G_{3}, G_{4}, G_{5}\right\}
$$

\subsection{Implementation of the fuzzy evaluation model}

The normalized value $\overline{\bar{V}}_{P}\left(C_{i}\right)$ was transformed into a triangular fuzzy number form $V_{P}\left(C_{i}\right)$, that is,

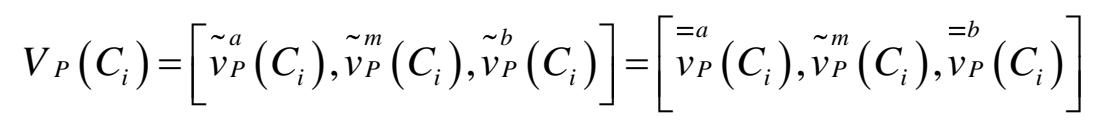

where, $\tilde{\nu}_{P}^{m}\left(C_{i}\right)$ is the optimal value of the evaluation index $\mathrm{i}$, which is generally $\widetilde{v}_{P}^{m}\left(C_{i}\right)=\frac{\bar{\nu}_{P}^{a}\left(C_{i}\right)+\bar{\nu}_{P}^{b}\left(C_{i}\right)}{2}$.

According to the construction of triangular fuzzy numbers [22-25], fuzzy membership functions of relevant evaluation levels can be constructed. Assuming that the fuzzy classic domain of the evaluation index $\mathrm{i}$ at the $\mathrm{j}$-th evaluation level is $V_{j}\left(C_{i}\right)=\left[\tilde{v}_{j}^{a}\left(C_{i}\right), \tilde{v}_{j}^{m}\left(C_{i}\right), \tilde{v}_{j}^{b}\left(C_{i}\right)\right]$, and $\tilde{v}_{j}^{a}\left(C_{i}\right)=\tilde{v}_{j}^{m}\left(C_{i}\right)<\tilde{v}_{j}^{b}\left(C_{i}\right)$, then its fuzzy membership function $\varphi_{i j}\left(v_{x}\right)$ of the index $\mathrm{i}$ is: 


$$
\begin{aligned}
& \varphi_{i j}\left(v_{x}\right)= \begin{cases}1 & v_{x} \leq \tilde{v}_{j}^{m}\left(C_{i}\right) \\
\frac{\tilde{v}_{j}^{b}\left(C_{i}\right)-v_{x}}{\tilde{v}_{j}^{b}\left(C_{i}\right)-\tilde{v}_{j}^{m}\left(C_{i}\right)} & \tilde{v}_{j}^{m}\left(C_{i}\right) \leq v_{x} \leq \tilde{v}_{j}^{b}\left(C_{i}\right) \\
0 & v_{x} \geq \tilde{v}_{j}^{b}\left(C_{i}\right)\end{cases} \\
& \text { If } \tilde{\boldsymbol{v}}_{j}^{a}\left(C_{i}\right)<\tilde{\boldsymbol{v}}_{j}^{m}\left(C_{i}\right)=\tilde{v}_{j}^{b}\left(C_{i}\right), \text { its fuzzy membership function } \varphi_{i j}\left(v_{x}\right) \text { is: } \\
& \varphi_{i j}\left(v_{x}\right)= \begin{cases}0 & v_{x} \leq \tilde{v}_{j}^{a}\left(C_{i}\right) \\
\frac{v_{x}-\tilde{v}_{j}^{a}\left(C_{i}\right)}{\tilde{v}_{j}^{m}\left(C_{i}\right)-\tilde{v}_{j}^{a}\left(C_{i}\right)} & \tilde{v}_{j}^{a}\left(C_{i}\right) \leq v_{x} \leq \tilde{v}_{j}^{m}\left(C_{i}\right) \\
1 & v_{x} \geq \tilde{v}_{j}^{m}\left(C_{i}\right)\end{cases} \\
& \varphi_{i j}\left(v_{x}\right)= \begin{cases}\left.C_{i}\right)<\tilde{v}_{j}^{m}\left(C_{i}\right)<\tilde{v}_{j}^{b}\left(C_{i}\right), \text { its fuzzy membership function } \varphi_{i j}\left(v_{x}\right) \text { is: } \\
\frac{v_{x}-\tilde{v}_{j}^{a}\left(C_{i}\right)}{\tilde{v}_{j}^{m}\left(C_{i}\right)-\tilde{v}_{j}^{a}\left(C_{i}\right)} & \tilde{v}_{j}^{a}\left(C_{i}\right) \leq x \leq \tilde{v}_{j}^{m}\left(C_{i}\right) \\
0 & x \notin\left[\tilde{v}_{j}^{a}\left(C_{i}\right), \tilde{v}_{j}^{b}\left(C_{i}\right)\right] \\
\frac{\tilde{v}_{j}^{b}\left(C_{i}\right)-v_{x}}{\tilde{v}_{j}^{b}\left(C_{i}\right)-\tilde{v}_{j}^{m}\left(C_{i}\right)} & \tilde{v}_{j}^{m}\left(C_{i}\right) \leq x \leq \tilde{v}_{j}^{b}\left(C_{i}\right)\end{cases}
\end{aligned}
$$

Considering the weight wi of the evaluation index i, the fuzzy membership degree $\varphi j$ of the evaluation object at the $\mathrm{j}$-th evaluation level is:

$$
\varphi_{j}=\sum_{i=1}^{n} w_{i} * \varphi_{i j}\left(v_{x}\right)
$$

Therefore, the level of the evaluation object can be determined according to the degree of fuzzy membership $\varphi \mathrm{j}$.

\section{Conclusion}

The main research contents and innovations of this paper are shown as follows:

1. This paper analyzes the performance of PE major students' innovation ability in colleges, discussed the promotion role of PE curriculum in the cultivation of their 
innovation ability, and points out the defects and problems in the current PE curriculum planning of colleges.

2. Relevant strategies and suggestions for the PE curriculum planning in colleges were given from the five aspects of objectivity, effectiveness, professional orientation, integration and logic, which then enhance the role of college PE curriculum planning in improving college students' innovative ability.

3. From the determination of the evaluation index set, normalization of the evaluation index, classification of the evaluation level, and implementation of the fuzzy evaluation model, it discusses the training effect of the PE majors' innovation ability based on the PE curriculum planning, and conducts a quantitative analysis for the effect evaluation of the PE curriculum planning on innovation ability.

4. Finally, aiming at the cultivation of PE major students' innovation ability, a systematic analysis was performed for the key links and contents of college PE curriculum planning to cultivate college PE majors' innovation ability; besides, a quantitative evaluation model for PE curriculum planning analysis was constructed. This study has good theoretical innovation and practical value.

\section{Acknowledgement}

Discussion on the reform of physical education curriculum in Heilongjiang province under the background of credit system. No.: SJGY20170102.

\section{$7 \quad$ References}

[1] Zhang, Y. B. (2018). From "plan" to "national standard": The evolution and characteristics of and inspirations from physical education major curriculum setup. Journal of Physical Education, 27(1): 93-98. https://doi.org/10.16237/j.cnki.cn44-1404/g8.2020.01.014.

[2] Pan, L. (2019). A big data-based data mining tool for physical education and technical and tactical analysis. International Journal of Emerging Technologies in Learning, 14(22): 220231. https://doi.org/10.3991/ijet.v14i22.11345

[3] Sum, K. W. R., Wallhead, T., Ha, S. C. A., Sit, H. P. C. (2019). Effects of physical education continuing professional development on teachers' physical literacy and selfefficacy and students' learning outcomes. International Journal of Educational Research, 2019(88): 1-8. https://doi.org/10.1016/j.ijer.2018.01.001.

[4] Yang, Y., Meng, L. (2019). Physical education motion correction system based on virtual reality technology. International Journal of Emerging Technologies in Learning, 14(13): 105-116. https://doi.org/10.3991/ijet.v14i13.10710

[5] Su, B., Wang, F. H., Zhang S. B., He, J. S. (2020). Research On the cultivation of innovative practice ability of Engineering College Students. Contemporary Education Research and Teaching Practice, (2): 202-203. https://doi.org/10.16534/j.cnki.cn139000/g.2020.0342.

[6] Zhu, Y. (2020). Construction of Evaluation Index System of College Students'Innovation and Entrepreneurial Competence. Journal of North China University of Water R esources and Electric Power (Social Science Edition), 36(1): 42-46. https://doi.org/10.1379 0/j.ncwu.sk.2020.008. 
Paper-Effect of Curriculum Planning for Physical Education in Colleges on Innovation...

[7] Forey, G., Cheung, L. M. E. (2019). The benefits of explicit teaching of language for curriculum learning in the physical education classroom. English for Specific Purposes, 54: 91-109. https://doi.org/10.1016/j.esp.2019.01.001.

[8] Egan, C. A., Webster, C. A., Stewart, G., Weaver, R. G., Russ, L., Brian, A., Stodden, D. F. (2019). Case study of a health optimizing physical education-based comprehensive school physical activity program. Evaluation and Program Planning, 72: 106-117. https:// doi.org/10.1016/j.evalprogplan.2018.10.006.

[9] Zeng, S. S., Li, L. P. (2019). Innovation and practice of "Trinity" physical education curriculum construction with characteristics of science and Engineering- Taking Changsha University of Science \& Technology as an example. Contemporary Sports Technology, 9(31): 91-92. https://doi.org/10.16655/j.cnki.2095-2813.2019.31.091.

[10] Zhang, Y. Z. (2013). Analyze on College Physical Education Professional Curriculum R eform from Competency Based Education Perspective. Journal of Nanjing Sport Institute, 27(6): 104-107. https://doi.org/10.15877/j.cnki.nsic.2013.06.021.

[11] Cong, C. R., Wang, Z. X. (2019). The Direction of P.E. Curriculum Reform in Application-Oriented Colleges and Universities. Journal of Kashi University, 2019, 40(6): 111-116. http://dx.doi.org/10.13933/j.cnki.2096-2134.2019.06.023.

[12] Wang, Q.M., Zhu, L. H. (2019). Analysis of basketball teaching mode under the new physical education curriculum reform in Colleges and Universities-Taking Nanjing University of Information Science \& Technology as an example. Sports World, 2019(10): 130-131. http://dx.doi.org/10.16730/i.cnki.61- 1019/g8.2019.10.079.

[13] Parson, L., Childs, B., Elzie, P. (2018). Using competency-based curriculum design to create a health professions education certificate program the meets the needs of students, administrators, faculty, and patients. Health Professions Education, 4(3): 207-217. https:// doi.org/10.1016/j.hpe.2018.03.008.

[14] Teixeira, Z., de Oliveira Vital, S. R., Vendel, A. L., de Mendonça, J. D. L., Patrício, J. (2020). Introducing fuzzy set theory to evaluate risk of misclassification of land cover maps to land mapping applications: Testing on coastal watersheds. Ocean \& Coastal Management, 184: 1-12. https://doi.org/10.1016/j.ocecoaman.2019.104903.

[15] Boukezzoula, R., Coquin, D., Nguyen, T. L., Perrin, S. (2018). Multi-sensor information fusion: Combination of fuzzy systems and evidence theory approaches in color recognition for the NAO humanoid robot. Robotics and Autonomous Systems, 100: 302-3163. https:// doi.org/10.1016/j.robot.2017.12.002.

[16] Abastante, F., Corrente, S., Greco, S., Ishizaka, A., Lami, I. M. (2019). A new parsimonious AHP methodology: Assigning priorities to many objects by comparing pairwise few reference objects. Expert Systems with Applications, 127: 109-120. https:// doi.org/10.1016/j.eswa.2019.02.036.

[17] Büyüközkan, G., Feyzioğlu, O., Havle, C. A. (2019). Intuitionistic Fuzzy AHP Based Strategic Analysis of Service Quality in Digital Hospitality Industry. IFAC-PapersOnLine, 52(13): 1687-1692. https://doi.org/10.1016/j.ifacol.2019.11.443.

[18] Güler, M., Büyüközkanal, G. (2019). Analysis of Digital Transformation Strategies with an Integrated Fuzzy AHP-Axiomatic Design Methodology. IFAC-PapersOnLine, 52(13): 1186-1191. https://doi.org/10.1016/j.ifacol.2019.11.359.

[19] Cavallaro, F., Zavadskas, E. K., Streimikiene, D., Mardani, A. (2019). Assessment of concentrated solar power (CSP) technologies based on a modified intuitionistic fuzzy topsis and trigonometric entropy weights. Technological Forecasting and Social Change, 140: 258-270. https://doi.org/10.1016/j.techfore.2018.12.009.

[20] Fedajev, A., Stanujkic, D., Karabasevic, D., Brauers, W. K., Zavadskas, E. K. (2020). Assessment of progress towards "Europe 2020" strategy targets by using the 
Paper-Effect of Curriculum Planning for Physical Education in Colleges on Innovation...

MULTIMOORA method and the Shannon Entropy Index. Journal of Cleaner Production, 244: 1-12. https://doi.org/10.1016/j.jclepro.2019.118895.

[21] Delgado, A., Romero, I. (2017). Environmental conflict analysis using an integrated grey clustering and entropy-weight method: A case study of a mining project in Peru. Environmental Modelling \& Software, 77: 108-121. https://doi.org/10.1016/j.envsoft.2015. $\underline{12.011 .}$.

[22] Nirmala, G., Uthra, G. (2019). AHP based on Triangular Intuitionistic Fuzzy Number and its Application to Supplier Selection Problem. Materials Today: Proceedings,16(Part 2): 987-993. https://doi.org/10.1016/j.matpr.2019.05.186

[23] Son, N. T. K. (2018). A foundation on semigroups of operators defined on the set of triangular fuzzy numbers and its application to fuzzy fractional evolution equations. Fuzzy Sets and Systems, 347: 1-28. https://doi.org/10.1016/j.fss.2018.02.003.

[24] Saini, N., Bajaj, R. K., Gandotra, N., Dwivedi, R. P. (2018). Multi-criteria Decision Making with Triangular Intuitionistic Fuzzy Number based on Distance Measure \& Parametric Entropy Approach. Procedia Computer Scienceg, 125: 34-41. https://doi.org/ 10.1016/j.procs.2017.12.007.

[25] Yeh, C. T. (2017). Existence of interval, triangular, and trapezoidal approximations of fuzzy numbers under a general condition. Fuzzy Sets and Systems, 310: 1-13. https://doi. org/10.1016/j.fss.2016.03.013.

\section{Author}

Huiqiu Guo, was born in Harbin, Heilongjiang province. She is an associate professor and has done her postgraduate. Her research direction is Sports humanities and sociology.

Article submitted 2020-04-01. Resubmitted 2020-05-13. Final acceptance 2020-05-14. Final version published as submitted by the authors. 